\title{
Adult-onset Still's disease complicated by hypercalcaemia: possible relationship with rapidly destructive polyarthritis
}

\author{
J M G W WOUTERS, ${ }^{1}$ P G A FROELING, ${ }^{2}$ AND L B A VANDE PUTTE
}

From the Departments of ${ }^{1}$ Rheumatology and ${ }^{2}$ Medicine, University Hospital St Radboud, Nijmegen, The Netherlands

SUMmARY A 34-year-old man with adult-onset Still's disease developed a striking hypercalcaemia during a rapidly destructive polyarthritis with extensive osteoporosis. The hypercalcaemia seemed to be primarily caused by inflammation-induced bone resorption. On prednisone the polyarthritis went into remission and the plasma calcium levels became normal. Other remarkable features in this case were a subluxation of the atlantoaxial joint, a brain-stem haemorrhage, transient hyperuricaemia and hyperuricosuria, and urolithiasis.

Adult-onset Still's disease is an uncommon clinical entity, characterised by high spiking fever, arthritis, an evanescent rash, lymphadenopathy, splenomegaly, serositis and leucocytosis. ${ }^{1-3}$ We here describe a patient with typical adult-onset Still's disease who developed a striking hypercalcaemia. Laboratory data as well as the fact that the hypercalcaemia was associated with rapidly destructive polyarthritis and osteopenia pointed to inflammation-induced bone resorption as the main causal factor. Hypercalcaemia has not so far been reported in patients with adult-onset Still's disease.

\section{Case report}

A 33-year-old man was admitted to a hospital in July 1980 with high spiking fever, an evanescent macular non-pruritic rash, and polyarthritis. Thorough investigation yielded no evidence of infectious disease, systemic lupus erythematosus, reactive arthritis, or rheumatic fever. A diagnosis of adult-onset Still's disease was made. In August 1980; he was discharged on aspirin $4.8 \mathrm{~g}$ daily and chloroquine $150 \mathrm{mg}$ daily. During the next 19

Accepted for publication 4 September 1984.

Correspondence to $\operatorname{Dr} J$ M G W Wouters, Departments of Rheumatology and Medicine, University Hospital St Radboud, Geert Grooteplein Z-8, 6500 HB Nijmegen, The Netherlands. months the polyarthritis remained active in spite of treatment with several non-steroidal antiinflammatory drugs and successively, D-penicillamine and aurothioglucose. In addition prednisone was administered from September 1980 till January 1982. In February 1982 he was admitted to our hospital for total hip replacement and recurrent renal colic. At that stage his treatment consisted of indomethacin $100 \mathrm{mg}$ daily and aurothioglucose 100 mg biweekly.

On examination the patient looked pale and showed active and severe polyarthritis. The Westergren erythrocyte sedimentation rate (ESR) was 99 $\mathrm{mm} / \mathrm{h}$, packed cell volume $33 \%$, white blood count $10.9 \times 10^{9} / 1$, with normal differential counts. The Rose-Waaler and latex fixation tests were negative. An antinuclear antibody test was positive. Creatinine was $126 \mu \mathrm{mol} / \mathrm{l}$ (normal $\leqslant 100 \mu \mathrm{mol} / \mathrm{l}$ ), uric acid $0.56 \mathrm{mmol} / \mathrm{l}$ (normal $\leqslant 0.40 \mathrm{mmol} / \mathrm{l}$ ), calcium after correction for hypoalbuminaemia $2.67 \mathrm{mmol} / \mathrm{l}$ (nor$\mathrm{mal} \leqslant 2.55 \mathrm{mmol} / \mathrm{l}$ ), ${ }^{4}$ phosphate $1.48 \mathrm{mmol} / \mathrm{l}$ (normal $\leqslant 1.20 \mathrm{mmol} / \mathrm{l})$. The daily calcium excretion varied between 4.2 and $6.2 \mathrm{mmol}$, the uric acid excretion between 3.2 and $5.6 \mathrm{mmol}$. Chemical analysis of a renal stone revealed urate, calcium, oxalate and magnesium. A roentgenogram of the cervical spine showed atlantoaxial subluxation of $5 \mathrm{~mm}$ in full flexion. 
After bilateral total hip replacement the patient was discharged in May 1982 on indomethacin 100 $\mathrm{mg}$ daily, aurothioglucose $50 \mathrm{mg}$ biweekly, and allopurinol $300 \mathrm{mg}$ daily. Shortly after discharge he suffered for a few weeks from diplopia and ptosis of the left eyelid. Laboratory studies yielded no evidence for disseminated intravascular coagulation.
Computed tomography revealed a small haemo导 rhage in the brainstem.

Readmission to hospital followed in July 1982 语 view of increased joint complaints, anorexias nausea, and vomiting. Aspirin $300 \mathrm{mg}$ daily was the only anti-inflammatory drug he used at that times On physical examination the patient looked pale

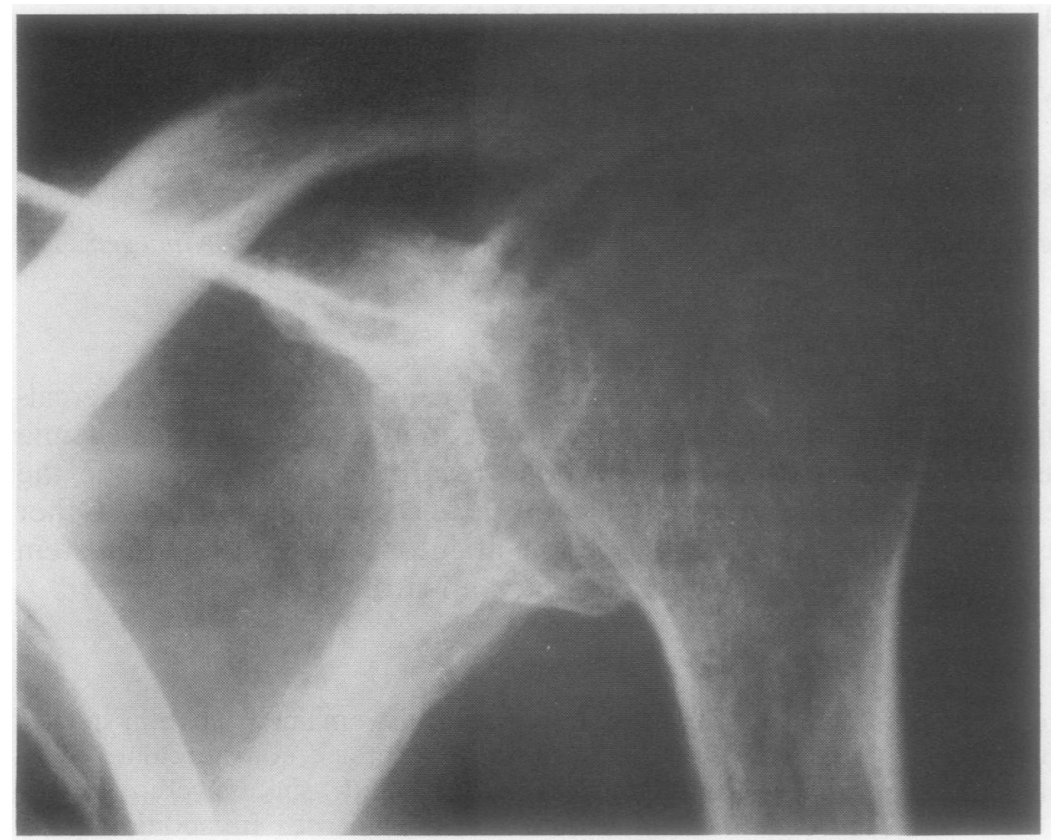

Fig. 1 Severe osteoporosis, join space narrowing and erosions of the left shoulder 2.5 years after onset.

plasma calcium calcium excretion ( $\mathrm{mmol} / \mathrm{l}$ )
/ day (mmol)

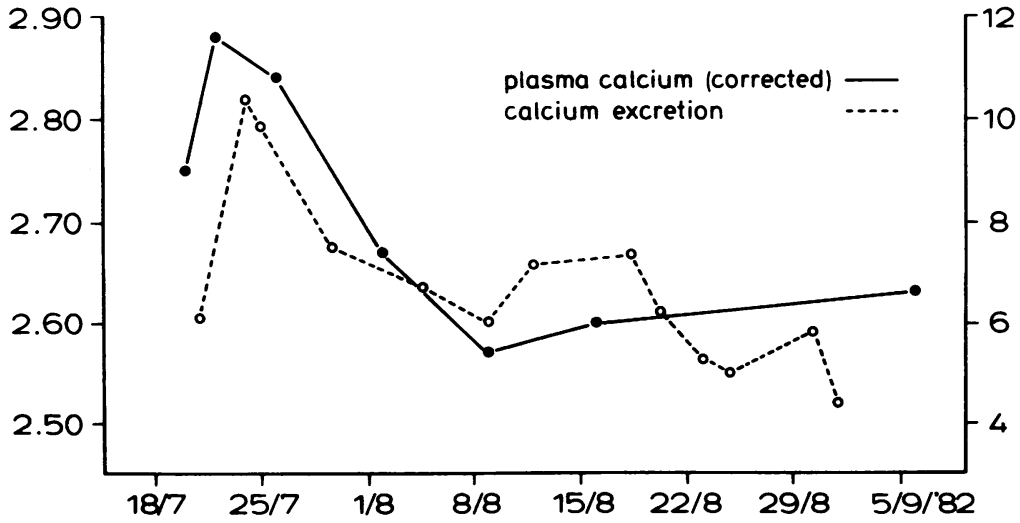

Fig. 2 Rapid decline of the 
slightly dehydrated, and cachectic. There was active arthritis of the shoulders, wrists, several finger joints, and the ankles. The ESR was $99 \mathrm{~mm} / \mathrm{h}$, packed cell volume $36 \%$, white blood count $18.1 \times 10^{9} / 1$ with a shift to the left, creatinine $107 \mu \mathrm{mol} / \mathrm{l}$, uric acid $0.40 \mathrm{mmol} / \mathrm{l}$, calcium after correction for hypoalbuminaemia $2.84 \mathrm{mmol} / \mathrm{l}$, phosphate $1 \cdot 18$ $\mathrm{mmol} / \mathrm{l}$. After rehydration of the patient the hypercalcaemia was further analysed.

\section{SPECIAL STUDIES}

The laboratory studies were performed after creatinine had fallen to $76 \mu \mathrm{mol} / \mathrm{l}$. Plasma calcium after correction for hypoalbuminaemia varied between 2.75 and $2.88 \mathrm{mmol} / \mathrm{l}$, serum phosphate between 1.36 and $1.49 \mathrm{mmol} / \mathrm{l}$, and 24 -hour calcium excretion between $6 \cdot 1$ and 10.4 mmol. 25-Hydroxycholecalciferol was $8.2 \mathrm{ng} / \mathrm{ml}$ (normal, in summer $>20 \mathrm{ng} / \mathrm{ml}$ ). Vitamin A was $<0 \cdot 1 \mu \mathrm{mol} / \mathrm{l}$ (normal $>1.05 \mu \mathrm{mol} / \mathrm{l}$ ). Serum immunoelectrophoresis revealed no evidence of paraproteins. Cortisol, parathormone, and thyroxine levels were normal. The intestinal calcium absorption after intake of $10 \mu \mathrm{Ci}$ ${ }^{47} \mathrm{Ca}$ was $12 \cdot 15 \%$ of the administered dose (normal $\geqslant 20 \%$ ). Roentgenograms of the joints showed severe osteoporosis, loss of joint space, and extensive erosive lesions at the shoulders, ankles, and several fingers and toes (Fig. 1). The wrists were fused. A roentgenogram of the chest was normal. A bone scan revealed increased uptake around nearly all peripheral joints and in the first cervical vertebra.

Aurothioglucose was stopped and prednisone 25 mg daily was started. On this treatment the polyarthritis came into a partial remission within four weeks. The plasma calcium levels declined rapidly (Fig. 2) and became normal in mid September 1982. Since May 1983 the polyarthritis has shown no more signs of activity with the patient on small doses of prednisone. The serum uric acid level and uric acid excretion remained normal after allopurinol was discontinued in September 1983.

\section{Discussion}

Adult-onset Still's disease was diagnosed in our patient in view of the presence of high spiking fever, an evanescent macular non-pruritic rash, and polyarthritis. ${ }^{1-3}$ The polyarthritis ran a very severe course. Within two years many peripheral joints showed severe osteoporosis, loss of joint space, and extensive erosive lesions. In addition a striking hypercalcaemia was observed, which seemed to be related to the activity of the polyarthritis. No evidence was found for other diseases causing hypercalcaemia-for example, malignant diseases, hyperparathyroidism, hyperthyroidism, vitamin A or D intoxication, sarcoidosis, or Addison's disease. The highest plasma calcium values were observed at a time when the patient was taking only $300 \mathrm{mg}$ aspirin daily. Treatment with prednisone resulted in remission of the polyarthritis and return to normal of the plasma calcium values.

The severe osteoporosis, extensive erosive lesions, and decreased intestinal calcium absorption suggest that the raised plasma calcium levels were caused by increased bone resorption. Although immobilisation certainly had a role in this case, hypercalcaemia due to immobilisation usually occurs only after considerable loss of renal function. ${ }^{5}$ Because our patient maintained high plasma calcium levels after restoration of his renal function, we presume that besides immobilisation some other mechanism was responsible for the increased bone resorption, probably increased prostaglandin synthesis. In-vitro studies have shown that synovial tissue of patients with rheumatoid arthritis produces large quantities of $\mathrm{PGE}_{2}$, which is able to stimulate osteoclastic bone resorption. ${ }^{6}$ Because $\mathrm{PGE}_{2}$ synthesis can be inhibited by antiinflammatory drugs, ${ }^{6} 7$ the above mentioned hypothesis would also explain the effects of treatment on the hypercalcaemia of this patient.

Raised plasma calcium levels have not so far been described in patients with adult-onset Still's disease, whereas there are a few conflicting reports about hypercalcaemia in rheumatoid arthritis. ${ }^{4-10} \mathrm{Be}$ sides hypercalcaemia our patient showed some other remarkable features; subluxation of the atlantoaxial joint, brain stem haemorrhage, transient hyperuricaemia and hyperuricosuria, and urolithiasis. The hyperuricaemia, probably caused by increased cell catabolism during the active phase of the illness, disappeared when the disease went into remission. Chemical analysis of a renal stone revealed urate, calcium, oxalate, and magnesium. It is assumed that urolithiasis with this composition is primarily caused by hyperuricosuria. ${ }^{11}$ The arthritis of adult-onset Still's disease generally runs a rather benign course. ${ }^{3}$ The joint destruction in this case, however, was so rapid and widespread that it gave rise to hypercalcaemia, promptly responding to anti-inflammatory treatment with prednisone.

\section{References}

1 Bywaters E G L. Still's disease in the adult. Ann Rheum Dis 1971; 30: 121-33.

2 Bujak J S, Aptekar R G, Decker J L, Wolff S M. Juvenile rheumatoid arthritis presenting in the adult as fever of unknown origin. Medicine (Baltimore) 1973; 52: 431-44.

3 Esdaile J M, Tannenbaum H, Hawkins D. Adult Still's disease. Am J Med 1980; 68: 825-30. 


\section{Wouters, Froeling, van de Putte}

4 Kennedy A C, Allam B F, Rooney P J, et al. Hypercalcaemia in rheumatoid arthritis: investigation of its causes and implications. Ann Rheum Dis 1979; 38: 401-12.

5 Claus-Walker J, Carter R E, Campos R J, Spencer W A. Hypercalcaemia in early traumatic quadriplegia. $J$ Chronic Dis 1975; 28: 81-90.

6 Robinson D R, Tashgran A H, Levine L. Prostaglandinstimulated bone resorption by rheumatoid synovia. J Clin Invest 1975; 56: 1181-8.

7 Kantrowitz F, Robinson D R, McQuire M B. Corticosteroids inhibit prostaglandin production by rheumatoid synovia. Nature 1975; 258: 737-9.

8 Mautalen C, Hofman J, Cabrejas M, et al. Bone and calcium metabolism in rheumatoid arthritis (abstract). Arthritis Rheum?
1982: 25: S38.

9 Bramble M G. Blake D R. White T. Sly J. Kerr D N S. Ionised calcium in rheumatoid arthritis: effect of non-steroidal antiinflammatory drugs. Br Med J 1980; 281: 840-1.

10 Scott D L. Farr M. Hawkins C F. Wilkinson R, Bold A M은 Serum calcium levels in rheumatoid arthritis. Ann Rheum Dis 1981; 40: 580-3.

11 Pak C Y C. Barilla D E. Holt K. Brinkley L. Tolentino Ra Zerwekh J E. Effect of oral purine load and allopurinol on the crystallisation of calcium in urine of patients with hypcrurico $\vec{O}$ suric calcium urolithiasis. Am J Med 1978; 65: 593-9. 